\title{
Representation of Women in Occupational and Domestic Roles in EfT Textbooks
}

\author{
Afroza Aziz Suchana \\ Assistant Professor, Department of English, University of Asia Pacific, Dhaka, Bangladesh \\ https://orcid.org/0000-0003-3910-4547
}

Manuscript ID:

ENG-2020-08043390

\begin{abstract}
The study aims at examining the representation of women in the English Language textbooks of Bangladesh for primary school learners. Existing research studies find the unfair manifestation of women both in occupational and domestic activities. However, the existing investigations indicate the necessity of further studies in this area. Therefore, the study explores whether women are projected appropriately in textbooks for young learners. With reference to critical theory, the analysis of data reveals that women are devalued in their unpaid domestic jobs. In addition, they are shown occupied in the less challenging occupations while men are shown in an extensive range of professions. The study also notices that whereas in contemporary Bangladesh, women are engaged in diversified professions, their contribution to society is often disregarded in the textbooks. Such a biased representation of women may affect the young learners adversely. Therefore, the study states the inevitability of raising consciousness among the textbook authors and suggests ensuring the appropriate projection of women in the textbooks.
\end{abstract}

Volume: 8

Year: 2020

P-ISSN: $2320-2645$

Keywords: Unpaid domestic works, Textbooks, Devaluation, Occupational role, Biased representation and Social reality

E-ISSN: 2582-3531

Received: 20.06.2020

\section{Introduction}

Textbooks are used as a core means of classroom teaching, especially for the primary level learners. Textual materials also act as a tool to develop social values. Children may learn about gender roles from textbooks. Hall (2014) remarks instructional materials as a powerful means of conveying genderbiased language. Textbooks are viewed as one of the means employed as a manipulative instrument for power relations (Ahour and Zaferani, 2016). Textual materials play highly significant roles in determining students' perceptions of female and male roles in society (Hall, 2014). Ahour and Zaferani (2016) state gender as one of the sociocultural issues that may be presented through the textbooks.

Hence, it is expected that textbooks should represent equal participation and status of females and males in the occupational and domestic roles. Women's occupational and domestic roles in the textbooks may represent their social status. When some higher-ranked or challenging occupations are assigned to men, and less challenging occupations are assigned to women, it shows the secondary status of women. Such discrimination may lead to stereotypical representations of gender.

Moreover, if textbooks project men in challenging jobs and women are shown busy in the household chores, young girls may perceive that this is the social practice. Moreover, such a biased representation of women may lower girls' expectations and motivation. Amruthraj (2012) views that the concept of sexism takes its root from the stereotyped representation of female characters in textbooks. He finds that women are mostly presented as mothers, workers and in low-status occupations. 
Hall (2014) defines sexism as a belief where one sex or gender is superior or more valuable than the other. "Sexism is commonly considered to be discrimination against people based on their sex rather than their merits" (Hall 2014, p.253). Hence, textbooks should represent the power and merits of both men and women in order to ensure equality.

This study analyses English for Today (EfT) books of Class IV and Class V published by the National Curriculum and Textbook Board (2019) with a view to exploring if any discrimination in the occupational and domestic roles of male and female characters exist. Various studies expose the underrepresentation of women professionally. In many cases, women are depicted only in household activities. Women's participation in economic activities is disregarded. Even if they are shown in professional roles, they are portrayed as teachers, nurses, or doctors, whereas men are portrayed in diversified occupations. Amruthraj (2012) notes that the significant contribution that women make to the economy and the well-being of their families is very often overlooked. In the context of Bangladesh, Kabir (2015) analyses some units of the EfT textbook of Class IX-X and notices stereotypical occupational and domestic roles of women. Such a biased representation of gender may have negative impacts on pedagogical values.

This study is pointedly important in the context of Bangladesh. In Bangladesh, gender discrimination is found in many cases. Here, women are mostly dependent upon men. As society is male-dominated, here men have more power and influence. Women and young girls are more underprivileged than men, whereas they have potentials and skills. If women get an equal opportunity like men, they can play significant roles in the socio-economic development of the country. To ensure women's participation, they need equal treatment inside and outside the home.

\section{Literature Review}

The depiction of gender roles has been a buzz word since the 1970s in social science research. The term 'gender' refers to masculinity and femininity (Diamond, 2002). Gender equity refers to "equal pay, equal access to opportunities to enter an occupation and to advance in it, and freedom from harassment" (Bailyn, 2003, p.139). Numerous research studies analyze gender roles in the textbooks. Findings reveal the unfair manifestation of women and men from the domestic to the occupational field.

Unpaid household works are often associated with women, whereas their male counterparts are presented in the creative works. Amruthraj notes that women are devalued across occupations. Economic value is not given to their works. For example, women's domestic activities include food processing, maintaining kitchen, gardening, looking after livestock, poultry, etc. which are all economic activities (Amruthraj, 2012). He also identifies stereotypical professional roles of female characters in the textbooks taught in government primary schools in Tamil Nadu, India. He notes a total of 31 occupations in the textbooks and traces that nurses and teachers in the are consistently women, while doctors, police officers, post persons, pilots, derivers, carpenter, and soldiers are all men. Such distinct professional roles display the depreciation of women.

Kabir (2015) also notices the stereotypical representation of women. He finds that men sometimes help women in the kitchen works, but in the professional sphere, women are underrepresented. Women are not depicted in varied professions like men. Male characters are portrayed as village chief, driver, vendor, or security guards, but no woman is found in such roles in Bangladeshi textbooks. However, Kabir's study points to the necessity of a more comprehensive study in this area.

The lack of female role models is uncovered by various research studies. Pakistani school textbooks reveal that gender disparity lies in the society, which is reflected and promoted through stereotypical roles presented in the textbooks (Munawar, 2004). Head teachers of 24 selected schools find gender disparity in the school textbooks. $62.5 \%$ of the Head teachers agree, and $33 \%$ of them strongly agree that textbooks portray stereotype roles of men and women (Munawar, 2004). Munawar's study reveals that gender disparity adversely affects female education. It also traces the connection between stereotypical representation of women and the dropout of female students. The study looks for the reasons and finds 
out that girls' early marriage and the tradition of not going for good jobs are significant reasons for the drop outs. It exposes that girls do not find their role models in the textbooks as women are not portrayed in non-traditional roles such as pilot, lawyer, and engineer. The findings of Munawar reflect the stereotypical professional roles of women. The study states that textbooks play a significant role in the choice of professions. Therefore, textbooks may inspire girls to break the norms and to motivate them to choose non-stereotypical and challenging professions.

Imbalance in both the domestic and professional gender roles is exposed in the Iranian textbooks by Hall (2014). Hall's examination indicates that males are presented in a wider range and overall a higher level of employment than females. Women's professional field is very limited such as they are occupied as a housekeeper, nurse, teacher, librarian, and doctor. On the contrary, men enjoy diversity in occupations ranging from lower-ranking to higher-ranking roles. Hall also evaluates the distribution of household responsibilities and reveals discrimination. In her study, Hall (2014) analyzed two Iranian textbooks. One of the textbooks shows that out of the total of 10 household responsibilities, eight are performed by females in the family. In contrast, males are only responsible for shopping and sharing the driving of family car with females. Hall mentions that such imbalanced representation may affect students' attitudes and dispositions and recommends including a wider range of occupational possibilities for women.

Thus, a review of existing literature shows that both the professional and domestic roles of women are devalued in the school textbooks. These studies provide the rationale for the present study. This study looks for whether men and women are equally presented in the domestic and occupational roles in the English language textbooks of Bangladeshi primary schools. If learners get examples of equal power and participation of males and females both in the household and professional works through textbooks from the beginning of their academic life, it may create positive impacts upon their minds. Therefore, both girls and boys will be equally motivated to work for society.

\section{Theoretical Construct}

This study traces critical theory as this theory focuses on consciousness. The critical theory views consciousness as both a revolutionary and liberating force (Nicholls, 2005). This theory seems effective in identifying gender roles in the occupational and domestic category and in raising social and cultural awareness. The critical theory looks at what is wrong in the current social reality. Apple (1986) connects between social reality and the textbook. He depicts how textbooks are influenced by capitalist society and brings out gender exploitation in teaching. This study analyses EfT textbooks by using critical theory, which seems to be an appropriate analytical tool to explore inequalities in the occupational and domestics roles of male and female characters.

\section{Methodology}

Qualitative content analysis method has been chosen in this study to investigate the representation of women in occupational and domestic roles in the Textbooks. Contents of the English for Today (EfT) textbooks of Class IV and Class V have been analyzed here. The content analysis approach is characterized as a systematic method to generate findings by White and Marsh (2006). By using this approach, the study observes whether the textbooks represent social values and aptitudes of women in both occupational and domestic activities.

\section{Data Analysis and Findings}

A total of 42 units are there in the EfT textbook of Class IV and 25 units in the book of Class V. Content analysis has been carried out to find out the representation of women in the occupational and domestic roles. Findings from the qualitative data analysis process along with the interpretation of data are presented below:

\section{Occupational Roles of Women in the EfT Textbook of Class IV}

The biased representation of women in occupation is found in the textbook of Class IV. Here women are presented in a limited range of occupations including teacher, doctor, nurse, singer, and garment worker. In contrast, men are presented in diversified occupations such as pilot, farmer, 
driver, postman, boatman, photographer, tailor, doctor, cleaner, dentist, etc.

In unit 3, lessons 1-2, the family of Farzana and Jamil have been portrayed. Here, Farrzana's mother has been presented as a doctor while her father is presented as a pilot. In the same unit, lessons 3-4 show Farzana's grandfather as a retired government officer and her grandmother as a homemaker.

In unit 15, lessons 1-3, Sagar's family has been introduced where his father is shown as a doctor, and his mother is a housewife. Sagar's grandfather is a retired schoolteacher, and his grandmother works at home. In unit 27, a female character Hasna Hena is presented as a teacher.

The title of unit 39 is occupations. In this unit, lesson 1 presents six characters in various occupations. Among them, only two are female who is presented as singer and doctor. In contrast, there are four male characters who are presented as farmer, driver, photographer, and postman. Similarly, unit 39, lesson 2 presents six characters in different occupations. Like lesson 1, here, only two are women, and four are men. The women are presented as teachers and nurses. The men are presented as cleaner, boatman, dentist, and tailor.

Besides these, in unit 40, lessons 1-2, a female character Reshma is presented as a garment worker. In unit 41, lessons 4-5, three images are depicted where one female character is shown as a cleaner, and two male characters are shown as a rickshaw driver and a guard.

\section{Occupational Roles of Women in the EfT Textbook of Class V}

Unequal representation of women in occupations is also noticed in the textbook of Class V. Here, female characters are shown as a teacher, doctor, and singer, whereas male characters are shown as NGO worker, banker, firefighter, guide and doctor.

In unit 1, lessons 4-5, presents a male character Andy Smith as an NGO worker. Unit 2, lessons 3-4 present Ms. Smith is shown as a teacher. Unit 16, lessons 1-2 also show a female character, Mrs. Alam, as a teacher.

In unit 3, lessons 1-2, Saikat's father is a banker and his mother is a housewife. In unit 9, lessons 1-2, a male character is shown as a firefighter. Lessons
3-4 of the same unit present a female character as a singer.

A guide is referred to as a male in unit 19, lessons 1-2. Male referent pronoun 'he' is used to talk about the guide that indicates his gender.

\section{Domestic Roles of Women in the EfT Textbook of Class IV}

In unit 15, lessons 1-3, Sagar's mother, who is shown as a housewife, grows tomatoes and cucumbers. She has a wonderful garden, but such laborious works of women are unpaid and typically devalued in society. In the same unit, Sagar's grandmother is shown working at home. She makes the best 'pithas' (rice cakes) in the world, according to Sagar. On the other hand, Sagar's grandfather is shown helping him in his studies. He (Sagar's grandfather) is also mentioned as very smart, but the females in the family are occupied in cooking and gardening and are not described as smart.

In unit 33, two images of a family are depicted where the family members are eating together. In the first image, the father seems very happy and appreciates the cooking. The second image shows that the mother cooked, and the children helped her. Therefore, the male character's participation is not found in the domestic role. Unit 35, lessons 1-2 present Alvi's grandmother in the stereotypical domestic roles through an image. She is shown busy cutting and cooking.

\section{Domestic Roles of Women in the EfT Textbook of Class V}

In the textbook of Class $\mathrm{V}$, women are mostly presented in domestic roles. In unit 3, lessons 1-2, Saikat's mother is shown as a housewife. Her evening activities include cooking, sewing, washing dishes after dinner, and watching TV whereas. Saikat's father is shown in writing in his leisure time, whereas her mother is shown busy with sewing through an image.

Saikat's family picture shows the stereotypical representation of women. His mother is only presented in domestic roles. The male character is not shown doing household chores.

In unit 16, lessons 1-2, Sufia's mother is shown monitoring her homework. Lessons 3-4 of the 
same group show Azim's mother is busy with the household chores.

\section{Interpretation of the Data}

Findings reveal that women are underrepresented both in the textbooks of Class IV and Class V. Women are mostly presented as teachers, doctors, singers, and nurse,s which expose limited scopes for women. In the textbook of class IV, Farzana and Jamil's father is shown as a pilot, which is a challenging position. Throughout the book, no woman is found in challenging professions. Munawar (2004), in his study, mentions the adverse effects of gender disparity in an occupation on female education. $\mathrm{He}$ traces that women in Pakistani textbooks are not found in the challenging professions like a pilot. This study exposes that Bangladeshi textbook also lacks women in such a position. The EfT textbook of Class $\mathrm{V}$ presents a male character as a firefighter, which is a challenging profession indeed, whereas women are presented in the less challenging professions. From such representations, young learners may perceive that challenging professions are not meant for females.

However, this is not always the social reality of contemporary Bangladesh. Though many women are still dominated by males, nowadays Bangladeshi women are showing their potentials in every sphere of society. This reality of society is ignored in the textbooks. As Apple (1986) exposes the connection between textbook and social reality, it is expected that the representation of women's success needs to be presented in the textbooks. Equal representation may motivate the learners to contribute to the society.

Both of the textbooks (Class IV-V) present men in a wide range of professions and women in very limited roles. A higher level of employment of one gender may affect learners' attitudes and dispositions (Hall 2014). Therefore, such discriminatory occupational roles may have adversarial effects upon young learners.

Also, one of the common features of genderbiased representation is engaging only women almost in all domestic roles. This study exposes that he EfT textbooks of Class IV and Class V exclude male characters from the household chores. The textbook of Class IV shows that a male character only appreciates cooking (in unit 33), but he is not involved in the domestic works. Moreover, in unit 15, Sagar's mother grows vegetables, which have economic value. Amruthraj (2012) finds that such unpaid household activities of women are not simply related to social reproduction, but very clearly economic. Such a contribution of women is too often ignored by society.

Thus, if textbooks project women's contribution to the society, female learners will be conscious of their power and potentials. Eventually, they will be responsive to work for the well-being of the society. Therefore, textbook writers should select appropriate content for the textbooks. To adapt gender-equitable materials, the consciousness of the textbook writers is highly significant.

\section{Conclusion}

The study revealed discriminatory occupational roles of men and women in the English language textbooks of Class IV and Class V. It exposes the engagement of women in the domestic works. Women, who are shown in different occupations, are presented in the stereotypical and less challenging professions. In contrast, men are presented in a wider range of occupations. Participations of male characters in the domestic activities are not found in the contents of the textbooks. However, characters of the textbooks may appear as role models to the young learners of the primary schools. Hence, if they find women in diversified occupations, they will be able to fix their future aims, goals, and visions accordingly.

Similarly, if they observe men's participation in the household chores along with women, both boys and girls will learn about equal responsibilities. Conversely, if the learners find stereotypical roles of women, that might lower girls' prospects and dreams. Thus, the gender role in occupational and domestic activities is a social phenomenon. Therefore, textbook writers need to choose gender impartial textbooks consciously.

\section{References}

Ahour, Touran, and Pardis Zaferani. "A Critical Visual Analysis of Gender Representation of ELT Materials from a Multimodal 
Perspective." Journal of Applied Linguistics, vol. 9, no. 18, 2016, pp. 78-98.

Amruthraj, R. M. "Gender Discrimination in the Primary School English language Textbooks in Tamil Nadu." The Primary Teacher, vol. 37, no. 1\&2, 2012, pp. 77-101.

Apple, Michael W. Teachers and Texts: A Political Economy of Class and Gender Relations in Education, Routledge, 1986.

Bailyn, Lotte. "Academic Careers and Gender Equity: Lessons Learned from MIT." Gender, Work \& Organization, vol. 10, no. 2, 2003, pp. 137-153.

Diamond, Milton. "Sex and Gender are Different: Sexual Identity and Gender Identity are Different." Clinical Child Psychology \& Psychiatry, vol. 7, no. 3, 2002, pp. 320-334. English for Today Class 4, National Curriculum and Textbook Board, Dhaka, Bangladesh, 2019.
English for Today Class 5, National Curriculum and Textbook Board, Dhaka, Bangladesh, 2019.

Hall, Mahnaz. "Gender Representation in Current EFL Textbooks in Iranian Secondary Schools." Journal of Language Teaching and Research, vol. 5, no. 2, 2014, pp. 253-261.

Kabir, M. "Representation of Women in Bangladeshi ELT Materials." The Dhaka University Journal of Linguistics, vol. 5-6, 2015, pp. 127-146.

Mirza, Munawar. Gender Analysis of School Curriculum and Textbooks, UNESCO, 2004.

Nicholls, Jason. "The Philosophical Underpinnings of School Textbook Research." ParadigmJournal of the Textbook Colloquium, vol. 3, no. 3, 2005, pp. 24-35.

White, Marilyn Domas, and Emily E. Marsh. "Content Analysis: A flexible methodology." Library Trends, vol. 55, no. 1, 2006, pp. 22-45.

\section{Author Details}

Afroza Aziz Suchana, Assistant Professor, Department of English, University of Asia Pacific, Dhaka, Bangladesh EmailID: suchanadu@gmail.com 